\title{
Study of Mechanical Properties and Microstructural behaviour of alpha- beta brass at elevated temperature
}

\author{
Bandhavi Challa ${ }^{1,2^{*}}$, Seeram Srinivasa Rao ${ }^{2}$ \\ ${ }^{1}$ Mechanical Engineering, Gokaraju Rangaraju Institute of Engineering and Technology, Hyderabad, India; \\ ${ }^{2}$ Mechanical Engineering, Koneru Lakshmaiah Education Foundation, Guntur, India.
}

\begin{abstract}
Deformation behaviour of metal can be analyzed by determining mechanical properties for optimizing workability. In the present investigation hot uniaxial tensile test for alpha - beta brass material have been performed by considering parameters like temperature $\left(\mathrm{RT}, 600^{\circ} \mathrm{C}\right.$ and $\left.700^{\circ} \mathrm{C}\right)$, strain rate $(0.1 / \mathrm{s}$, $0.01 / \mathrm{s}$ and $0.001 / \mathrm{s}$ ) and orientation (RD, ND and TD). The various material properties such as ultimate tensile strength $(\sigma \mathrm{u})$, yield stress $(\sigma \mathrm{y})$, total elongation $(\%)$ have been evaluated over the range of temperatures, strain rates and orientation. It have been observed that changes in material properties with respect to temperature, strain rate than orientation. The material properties has been analyse the mechanical characteristics of the material. The fractured specimens at various temperatures are studied and analyzed the failure modes in the material using Scanning Electron Microscope (SEM). SEM study confirms carbides and shear band which indicate predominantly ductile fracture in all the cases.
\end{abstract}

Keywords: Alpha-beta brass, hot uniaxial tensile test, material properties and scanning electron microscope.

\section{Introduction}

Brass is an alloy of copper and zinc, it has an exceptional mechanical and electrical properties. At elevated temperatures alpha - beta brass alloy had good applications in hot working conditions by various extrusion, die casting and stamping processes. Brass alloy are mainly used as fasteners, electric components, appliances and ammunition connectors [1-3]. Brass is popular for musical instruments like horns and bells, fashion jewellery, imitation jewellery and other costume jewellery. Manufacturing of miniature gears were also done by using brass alloys. In brass alloys, zinc content play a key role[4, 5]. Mainly, alpha and beta ratio are determined by knowing percentage of zinc present in the alloy. Other elements such as tin, aluminium and silicon also helps to improve properties of beta phase in this alloy. Alpha- beta brass are majorly used in hot working conditions, having good ductility property machinability, resist cracking and high strength to forming. Brass is one of the best best alloying material for medical applications, as brass having low reproducing capability for bacteria, brass can extensively used in doorknobs, bathroom locks and fixtures. The major drawback of alpha-beta brass are more influenced to dezincification, black tarnishing, non-destructive phenomenon and corrosion property when material is exposed to air. These limitations are overcome by proper maintenance.

These materials are finds applications at elevated temperatures, so it is very important to analyze and study the mechanical properties of the material at elevated temperatures. Beta phases in this alloy improves overall mechanical properties of the material and fine grain structure. The hot tensile deformation test helps to perform different test like compression test, uniaxial tensile test and biaxial tensile test.

Microstructural analysis of the brass shows comparatively complex plasticity region. In sheet metal forming process for manufacturing brass components time and cost plays a major role. So research has to be analyzed in safe and failure mode at various strain rates [6-10]. Most of the researchers reported that in tensile test, as strength increases ductility decreases because of strain hardening. At higher temperatures material becomes softer and ductility behaviour increases[11,12]. Spring back effect can also be minimized. With the above applications and various parameters selection is useful to form intricate shapes of the components. The influence of various strain rates and dynamic conditions are discussed in the literature survey[13-17]. However, more insight are needed to investigate the material properties and microstructure studies of alpha - beta brass at elevated temperatures and strain rates.

In the present work, the hot deformation behavior of a cold-rolled Brass alloy was investigated using tensile tests from $\mathrm{RT}, 600^{\circ} \mathrm{C}$ and $700^{\circ} \mathrm{C}$ and strain rate range from 0.001- $0.1 \mathrm{~s}-1$. Additionally, microstructure studies have been carried out using SEM.

*Bandhavi Challa: challa.bandhavi@gmail.com 


\section{Experimental Procedure}

In the present study, alpha - beta brass cold-rolled sheet of thickness $0.8 \mathrm{~mm}$ was used for the tensile test. The chemical composition evaluated by optical emission spectrometry is mentioned in Table 1 .

Table 1. Chemical composition of brass alloy

\begin{tabular}{|l|l|l|l|l|l|}
\hline Element & $\mathrm{Cu}$ & $\mathrm{Pb}$ & $\mathrm{Fe}$ & $\mathrm{Zn}$ & $\mathrm{B}$ \\
\hline wt.\% & 61.6429 & 0.0682 & 0.0745 & REM & 0.0819 \\
\hline
\end{tabular}

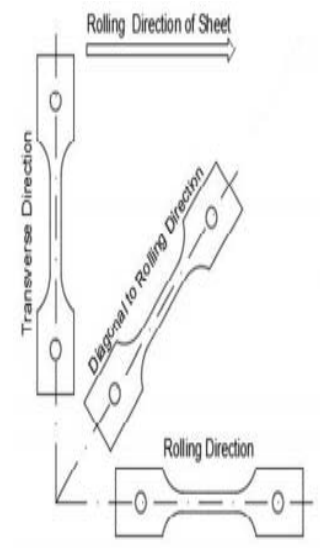

(a)

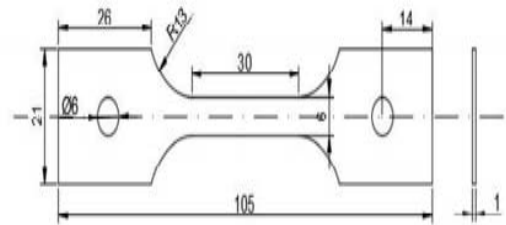

(All dimensions are in mm)
Fig. 1. Schematic representation of tensile specimen (a) with various orientation (b) sub sized sample ASTM E08/E8M-11 standard

Test samples were prepared in rolling, normal and transverse directions as shown in Fig.1 (a). Then prepared specimens were as per standard sub-sized ASTM E08/E8M-11 dimensions as shown in Fig. 1(b). The tensile samples were cut using the Electro Discharge machining(EDM) process to have a clean, fine finishing, damage-free and less distorted specimen. Samples are then subjected to a isothermal tensile experiment using a Computer-Controlled UTM as shown in Figure 2. with maximum load capacity of $100 \mathrm{kN}$.

Cylindrical heating two-zone split furnace with $\mathrm{K}$ type thermocouple is used to achieve required elevated temperatures. Hot uniaxial tensile test were conducted at temperature of $\mathrm{RT}, 600^{\circ} \mathrm{C}$ and $700^{\circ} \mathrm{C}$ with quasi static strain rates $(0.1,0.01$ and $0.001 \mathrm{~s}-1)$ and three orientation with respect to the rolling direction. The true stress vs true strain data is obtained from all the test. Also, mechanical properties such as Percentage Elongation (\%), Yield Strength(Ys), Ultimate Tensile strength( $\sigma \mathrm{u})$ and Strain hardening exponent (n) are calculated from experimental results. These obtained results helps us to know the behaviour of the material.

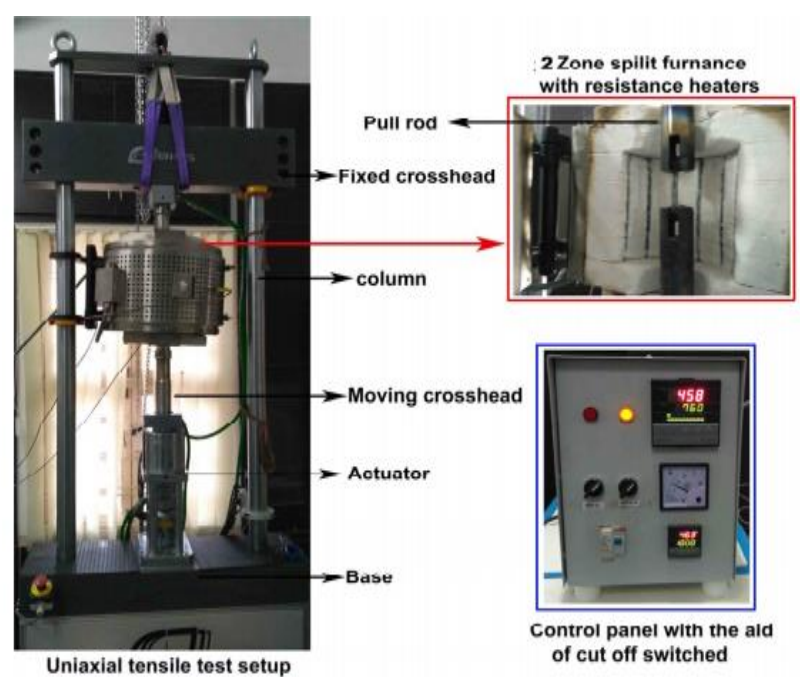

Fig. 2. Computer controlled UTM with high temperature two zone split furnace

\section{Results and discussion}

\subsection{Flow stress behaviour}

Effect of temperature, orientation and strain rates of brass has been studied and analysed flow behaviour of the material. It was observed that flow behaviour in stress-strain graphs considered by change in temperature. Fig. 3 (a) shows effect of temperatures (RT, $600^{\circ} \mathrm{C}$ and $700^{\circ} \mathrm{C}$ ) on tensile flow behaviour of Brass for different orientations. It is noticed that with rise in temperature affect the yield stress. The yield stress decreases with rise in temperature. This behaviour is observed mainly due to the softening phenomenon at elevated temperatures. This is the most common in most of the metals in tensile test $[18,19]$. Reduction in yield stress is caused due to thermal dislocation motion, results in plastic deformation at higher temperatures. Fig. 3 (b) shows the effect of strain rate $(0.1,0.01$ and $0.001 \mathrm{~s}-1)$ on Brass at $700^{\circ} \mathrm{C}$ temperature. With rise in strain rate flow stress value rise to yield stress values and inversely proportional with elongation. At lower strain rates, steady flow behaviour is observed. Fig. 3 (c) shows effect of orientation in flow behaviour at $700^{\circ} \mathrm{C}$ temperature strain rate of $0.1 / \mathrm{s}$. variation in orientation at particular temperature and strain rates has lesser impact. It is observed that \% elongation is comparatively lower in normal direction to that of rolling and transverse directions. At low strain rates higher \%elongation is exhibited.

Mechanical properties of the brass alloy is listed in Table 2 shows that flow behaviour is mainly depends upon the change in temperature and strain rates. The experimental data and calculated results shows that, as temperature increases yield strength and ultimate tensile strength decreases. But percentage elongation increases with increase in temperature. 


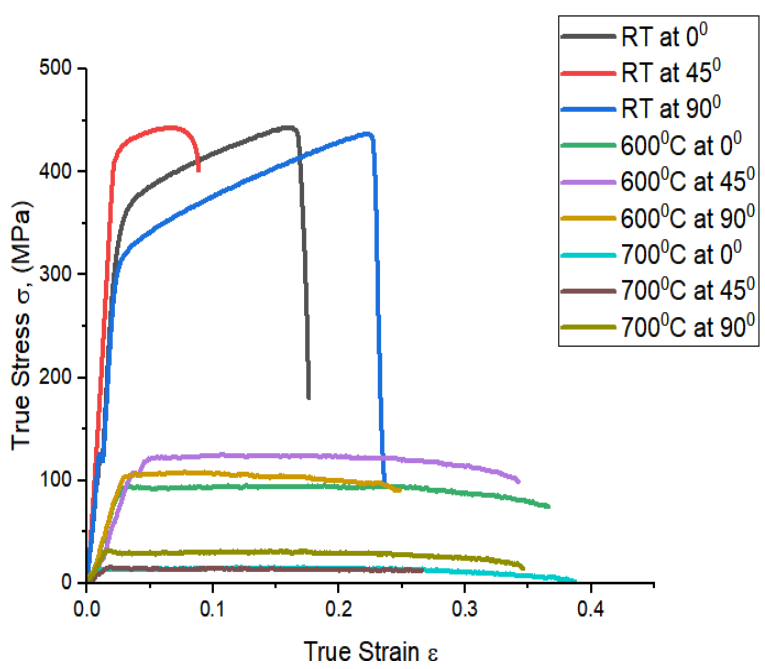

(a)

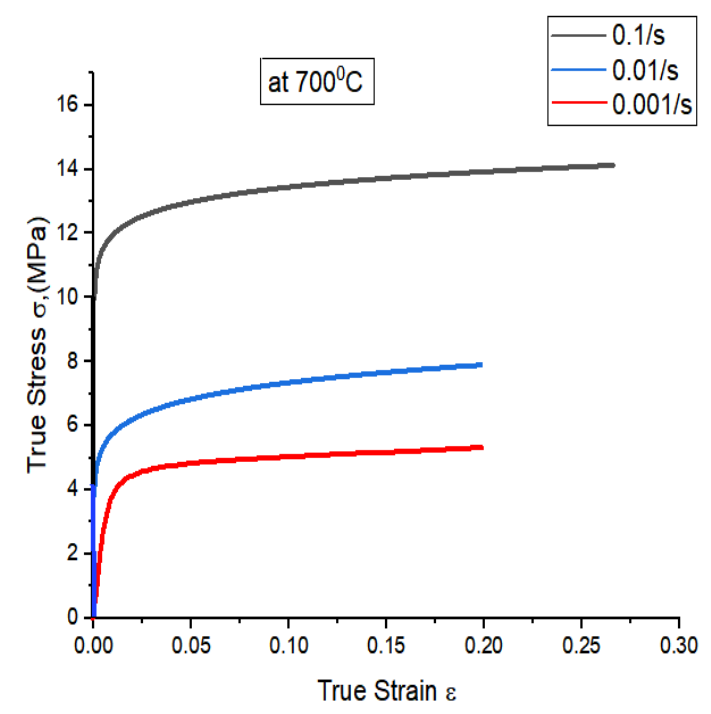

(b)

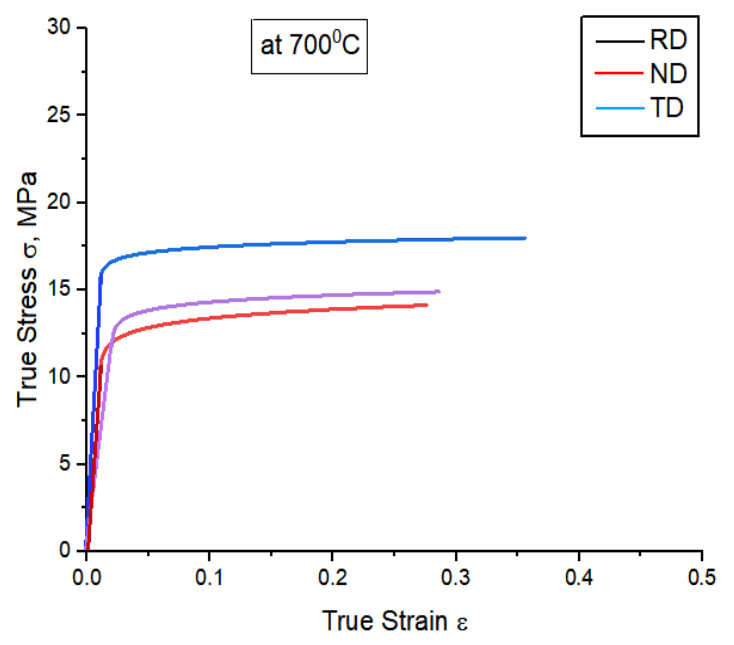

(c)

Fig. 3. Representation of True stress vs True strain (a) with various temperatures and orientation (b) with variation of strain rate at $700^{\circ} \mathrm{C}(\mathrm{c})$ with variation of orientation at $700^{\circ} \mathrm{C}$
Table 2: Material properties of Brass at various temperatures

\begin{tabular}{|l|l|l|l|l|}
\hline $\begin{array}{l}\text { Temp } \\
\left({ }^{\circ} \mathrm{C}\right)\end{array}$ & Orientation & $\begin{array}{l}\text { Yield } \\
\text { Strength } \\
(\mathrm{MPa})\end{array}$ & $\begin{array}{l}\text { Ultimate } \\
\text { tensile } \\
\text { strength } \\
(\mathrm{MPa})\end{array}$ & $\begin{array}{l}\text { Elongation } \\
(\%)\end{array}$ \\
\hline \multirow{3}{*}{$\mathrm{RT}$} & $\mathrm{RD}$ & 364.18 & 380.14 & 19.21 \\
\cline { 2 - 5 } & $\mathrm{ND}$ & 357.92 & 376.14 & 17.86 \\
\cline { 2 - 5 } & $\mathrm{TD}$ & 357.93 & 380.70 & 24.63 \\
\hline \multirow{3}{*}{600} & $\mathrm{RD}$ & 89.17 & 90.86 & 44.24 \\
\cline { 2 - 5 } & $\mathrm{ND}$ & 115.40 & 116.08 & 40.80 \\
\cline { 2 - 5 } & $\mathrm{TD}$ & 101.22 & 104.69 & 42.24 \\
\hline \multirow{3}{*}{700} & $\mathrm{RD}$ & 12.94 & 14.15 & 47.24 \\
\cline { 2 - 5 } & $\mathrm{ND}$ & 13.86 & 15.40 & 30.47 \\
\cline { 2 - 5 } & TD & 18.28 & 20.71 & 41.33 \\
\hline
\end{tabular}

\subsection{Fractography}

Scanning Electron Microscope (SEM) are used to investigate fracture surface of the tensile test samples. Fig. 4(a),(b) shows carbides and in-homogeneity of precipitates. This irregular carbides have both corrosion and oxidation property to the material. Due to the presence of carbides at grain boundaries, at elevated temperature the material strength gets rupture. Shear fracture and voids are observed in SEM images. At higher magnification micro voids can be seen clearly. Therefore, shear bands and dimples presence indicates ductile failures.

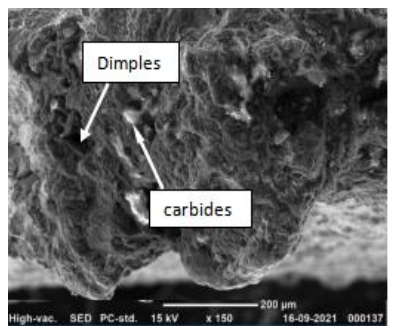

(a)

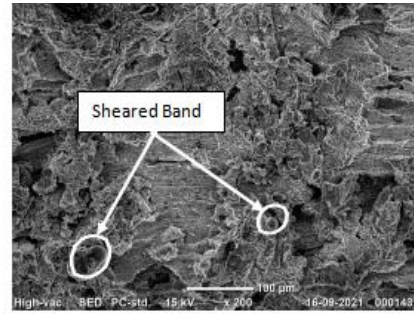

(b)
Fig. 4. Fractography images of fracture tensile specimens at $700^{\circ} \mathrm{C}$ in $\mathrm{RD}$ (a) $150 \mathrm{X}$ magnification (b) 200X magnification

\section{Conclusion}

In this work, hot uniaxial tensile tests were performed and studied the material properties. Fractography of alpha-beta Brass alloy at elevated temperatures are conducted to analyse the tensile test behaviour. The following conclusions are drawn from the above analysis:

1. The tensile flow behaviour is mainly affected due to temperature, strain rate and orientation. As temperature 
increases, yield strength and ultimate tensile strength are decreased. It is also observed that with rise in temperature percentage elongation is improved it indicates that good workability at elevated temperatures. 2. SEM micrograph shows carbides as well as the material in homogeneous distribution of large no of precipitates. Mixture of shear bands and shallow dimples have been observed in fractography which indicate ductile failure.

Future work includes further detail analysis of material properties variation and flow behavior using EBSD, EDS and TEM analysis

\section{References}

1. Young, W. S. Green Electronics. In Encyclopedia of Materials: Science and Technology, Elsevier,2001

2. Brandt, M. J.; Johnson, K. M.; Elphinston, A. J.; Ratnayaka, D. D. Specialized and Advanced Water Treatment Processes. In Twort's Water Supply; Elsevier, 2017

3. Wright, R. N. Relevant Aspects of Copper and Copper Alloy Metallurgy. In Wire Technology; Elsevier, 2016

4. Rehren, T. Small Size, Large Scale Roman Brass Production in Germania Inferior; 1999

5. Gupta, K.; Jain, N. K.; Laubscher, R. Introduction to Gear Engineering. In Advanced Gear Manufacturing and Finishing; Elsevier, 2017

6. Asgari, S.; El-Danaf, E.; Kalidindi, S. R.; Doherty, R. D. Metall. Mater. Trans. A Phys. Metall. Mater. Sci., 1997

7. Duggan, B. J.; Hatherly, M.; Hutchinson, W. B.; Wakefield, P. T. Met. Sci., 1978

8. El-Danaf, E.; Kalidindi, S. R.; Doherty, R. D.; Necker, C. Acta Mater., 2000

9. Farabi, E.; Zarei-Hanzaki, A.; Abedi, H. R. J. Mater. Eng. Perform., 2015

10. Fan, R.; Magargee, J.; Hu, P.; Cao, J. Mater. Sci. Eng. A, 2013

11. Mahalle, G.; Kotkunde, N.; Gupta, A. K.; Singh, S. K. Adv. Mater. Process. Technol., 2020

12. Bandhavi, ch.; S S Rao,; Pradeep, M,; Tanya, B,; Kosaraju, S,. Adv. Mater. Process. Technol., 2021

13. Padmavardhani, D.; Prasad, Y. V. R. K. Metall. Trans. A, 1991

14. Xiao, Y. H.; Guo, C.; Guo, X. Y. Mater. Sci. Eng. A, 2011

15. Padmavardhani, D.; Prasad, Y. V. R. K. Metall. Trans. A, 1991

16. Mohammed, A. A. S.; El-Danaf, E. A.; Radwan, A. K. A. Mater. Sci. Eng. A, 2007

17. Sakharova, N. A.; Fernandes, J. V.; Vieira, M. F. Mater. Sci. Eng. A, 2009

18. Dieter, G. E. Mechanical Metallurgy SI Metric Edition; 2011.
19. Fang, X. T.; He, G. Z.; Zheng, C.; Ma, X. L.; Kaoumi, D.; Li, Y. S.; Zhu, Y. T. Acta Mater., 2020 